\title{
Vitamin A and E content of commercial infant afoods in the UK: a cause for concern?
}

\section{Emma Loughrill a , Pesila Govinden ${ }^{b}$, Nazanin Zand ${ }^{\text {a,1 }}$}

${ }^{a}$ Faculty of Engineering and Science, University of Greenwich, Medway Campus, Chatham Maritime, Kent, ME4 4TB, UK

${ }^{b}$ Natural Resources Institute, University of Greenwich, Medway Campus, Chatham Maritime, Kent, ME4 4TB, UK

\section{ABSTRACT}

According to the European Food Safety Authority, currently, there are no reliable data or robust guidelines available in relation to the micronutrient composition of infant foods. This study evaluated the intake of vitamins A and E of infants from 'ready-to-feed' foods and formulas. Normal phase high performance liquid chromatography was employed for simultaneous quantification of retinyl acetate, retinyl palmitate, $\alpha$ tocopherol and $\gamma$-tocopherol, reverse phase high performance liquid chromatography for the quantification of $\beta$-carotene, and UV spectrophotometry for the quantification of carotenoids from selected infant food samples. Based on the results of this study, the estimated total daily intake of vitamin A (retinol equivalents) and vitamin E ( $\alpha$-tocopherol equivalents) from both infant food and formula milk exceed

\footnotetext{
${ }^{1}$ Corresponding author. Tel: + 44 (0) 208-331-8225; Fax: + 44 (0) 208-331-8305

E-mail address: N.ZandFard@greenwich.ac.uk (N. Zand)
} 
recommendations set by the UK Department of Health. This requires further analysis of risk of exposure, whilst a cause for concern over deficiency might arise when the intake of milk is compromised.

Key words:

Infants

Commercial complementary foods

Retinyl acetate, retinyl palmitate, $\beta$-carotene

$\alpha$-tocopherol, $\gamma$-tocopherol

Vitamin E, Vitamin A and carotenoids

HPLC

Toxicity

\section{Introduction}

Vitamin A consists of a group of lipid-soluble vitamins that have an important role in growth and development, vision and immune function. Dietary vitamin A is obtained from two sources: pre-formed vitamin A and pro-vitamin A. Pre-formed vitamin A includes retinol, retinal, retinoic acid and retinyl esters, which are available from animal sources mainly in the form of retinyl esters. Conversely, pro-vitamin A precursors in the form of carotenoids are available from plant-derived foods (Department of Health, 1991). Plants synthesise hundreds of carotenoids, but only 
some act as vitamin A precursors. $\beta$-carotene is the most important carotenoid due to its vitamin A activity compared with other carotenoids, and its widespread availability in the diet. $\beta$-carotene can be converted into two retinal molecules. Absorption rates of pre-formed vitamin A range between 70 - 90\%, whereas pro-vitamin A compounds are absorbed less efficiently at rates ranging between 20 - 50\% (Preedy, 2012).

Vitamin $\mathrm{E}$ is another group of lipid-soluble vitamins consisting of eight isomers: four tocopherols $(\alpha, \beta, \gamma$ and $\delta)$ and four tocotrienols $(\alpha, \beta, \gamma$ and $\delta)$. The most biologically active form of vitamin $\mathrm{E}$ is $\alpha$-tocopherol, which is also the most abundant form in the European diet due to consumption of olive and sunflower oils (Wagner, Kamal-Eldin and Elmadfa, 2004).

Vitamin E functions primarily as a chain breaking antioxidant. It protects membrane phospholipids from peroxidation and prevents free radical generation in cell membranes (Greene, Hambidge, Schanler and Tsang, 1988). $\alpha$-Tocopherol can intercept free radicals and prevent the oxidation of the lipids in cell membranes. (Baydas, et al., 2002). Immune system cells contain the most vitamin E, arguably because of their exposure to high levels of oxidative stress (Suskina \& Tontisirin, 2001). A maternal feeding study observed an association between increased intakes of vitamin E and decreased childhood wheeze and asthma (Devereux, et al., 2006). Therefore, vitamin E might have a role in the prevention of asthma and allergic disease inflammation, the incidence of which are increasing in the UK. Oxidative stress and inflammation also have a role in cardiovascular disease and cancer. However, current understanding of the role of vitamin $\mathrm{E}$ in these diseases remains unclear (Lee et al., 2005). 
Dietary polyunsaturated fatty acid (PUFA) intake influences tissue fatty acid content, and the amount of vitamin E required to prevent lipid peroxidation is directly related to PUFA intake (Greene, et al., 1988). The bioavailability and metabolism of vitamin E is largely unclear, ranging between 10 - 79 \%; nevertheless factors have been identified that affect vitamin E uptake and utilisation within the body, such as the food matrix and the amount and type of fat (Borel, Preveraud, and Desmarchelier, 2013).

During food processing, retinoids and carotenoids can undergo isomerization due to exposure to acids, heat and light. Thermal treatments can cause either isomerization, from trans to cis, or oxidation. However, heating can also promote carotenoid absorption, possibly due to the release of carotenoids from the food matrix. Homogenization of foods can also improve the availability of carotenoids. Processing methods, such as dehydration, blanching and canning, can cause either oxidation or isomerization of carotenoids (Klein \& Kurilich, 2000). However, retinol and carotenoids have been found to be relatively stable during most cooking procedures with industrial food processes, such as pasteurization and sterilization, generally, only resulting in small losses (Committee on Toxicity, 2012). Processing of foods, such as drying in the presence of air and sunlight, addition of organic acids, milling and refining, irradiation and canning, have been shown to reduce the vitamin E content, along with high temperatures, prolonged storage and high moisture content. Seasonal changes in vitamin E levels have also been shown in food products (Eitenmiller \& Lee, 2004). Therefore, the actual content of vitamin E in commercial infant foods might vary due to processing and seasonality of products used in production.

The diet and nutrition survey of infants and young children (DNSIYC) identified that 58\% of children who are fed foods other than milk have eaten a commercial baby or toddler meal (Lennox, Sommerville, Henderson \& Allen, 2013). These results indicate that commercial baby and 
toddler meals are major dietary contributors to an infant's nutritional intake; therefore, these products need to be assessed for their nutritional adequacy. Furthermore, there is currently no clear and complete analytical nutritional data available for commercial 'ready-to-feed' complementary infant foods in the UK. McCance and Widdowson ( $7^{\text {th }}$ Edition), UK food composition tables, contains limited data on the composition of commercial infant foods and, in addition, analytical techniques and nutrient data contained might now be out-dated. It is essential that food composition tables be updated regularly with the foods currently available on the market (Food Standard Agency, 2014).

DNSIYC has shown that mean intakes of vitamin A and E are close to or in excess of Recommended Nutrient Intake (RNI) (Lennox, et al., 2013). Furthermore, in the US, 35\% of toddlers exceed the Tolerable Upper Intake Level (UL) of $600 \mu \mathrm{g} /$ day for vitamin A, and vitamin E intakes were found to exceed the recommended adequate intakes in infants below 12 months (Butte, et al., 2010).

Vitamin A deficiency is common in developing countries with symptoms including visual impairment (Department of Health, 1991). However, in developed countries, such as the UK, excess vitamin A intakes may be more of an issue. Excess retinol can cause liver and bone damage, hair loss, double vision, vomiting and headaches. It can also decrease vitamin C storage, antagonise the action of vitamin K blood clotting function, and have anti-thyroid effects (Committee on Toxicity, 2014). Toxicity usually arises from chronic ingestion, exceeding the ability of the liver to store or metabolise excess vitamin A.

Potentially, high vitamin E intakes could impact absorption of the other fat-soluble vitamins, such as vitamin A, D and K. Infants have low vitamin $\mathrm{K}$ levels and studies have indicated that individuals with low vitamin K levels should not consume excess vitamin E, which can lead to 
blood clotting problems (Diplock, et al., 1998). High intakes of vitamin E could also have a pro-oxidant effect, due to the production of $\alpha$ tocopherol radicals. However, if antioxidant systems are balanced, for example by the sparing effect of vitamin C, these detrimental effects will not be exhibited (Rietjens, et al., 2002). Vitamin E is one of the least toxic vitamins and no evidence of negative effects of vitamin E that occurs naturally in foods have been observed (Eitenmiller \& Lee, 2004).

This study assessed the intake of vitamin A (pre-formed vitamin A, retinyl palmitate and retinyl acetate and pro-vitamin A, $\beta$-carotene and total carotenoid content as retinol equivalents, RE) and vitamin $\mathrm{E}$ ( $\alpha$-tocopherol and $\gamma$-tocopherol as $\alpha$-tocopherol equivalents, $\alpha$-TE) based on a diet consisting of commercial 'ready-to-feed' infant foods and infant formulas in the form of a standardized menu, as suggested by Zand, Chowdhry,

Pullen, Snowden and Tetteh (2012), and the results compared with current recommendations to assess likely infant intakes.

\section{Materials and methods}

\subsection{Chemicals}

Retinyl acetate, retinyl palmitate, $\beta$-carotene, methyl tert-butyl ether (MTBE), $\alpha$-tocopherol and $\gamma$-tocopherol were obtained from Sigma Aldrich (Poole, UK). The reference material (ERM - BD600) was purchased from the Institute for Reference Materials and Measurements for Certified Reference materials (Geel, Belgium). HPLC-grade iso-hexane, ethyl acetate, absolute ethanol, methanol, tetrahydrofuran (THF), and laboratory reagent grade sodium chloride $(\mathrm{NaCl})$, petroleum ether $(\mathrm{PE})\left(\mathrm{bp} 40-60^{\circ} \mathrm{C}\right)$ and anhydrous sodium sulphate were obtained from Fisher Scientific (Loughborough, UK). 


\subsection{Sample collection}

Eight different baby food samples were obtained from leading supermarkets in the UK between June and July 2014. The samples represented four popular brands available on the market (Statista, 2008). All brands were represented by two different product categories: (i) meat- and (ii) vegetable-based. The main ingredients of the baby food samples and their characteristics are presented in Table 1. Three independent replicates of samples were analysed from the same batch. The samples were stored unopened at room temperature, similar to their distribution and market environment.

\subsection{Sample preparation for retinyl acetate, retinyl palmitate, $\alpha$-tocopherol and $\gamma$-tocopherol analysis}

Each of the food samples was homogenized using a domestic blender (Multi-quick, Braun 3000), and three independent replicates of $1 \mathrm{~g}$ (wet weight) were transferred to a centrifuge tube. The samples were treated according to the methods described by Chávez-Servín, Castellote and Lopez-Sabater (2006). Briefly, absolute ethanol ( $3 \mathrm{~mL}$ ) was added to the sample and the mixture shaken mechanically for 3 minutes prior to addition of hexane $(1 \mathrm{~mL})$. The mixture was shaken for a further minute. Then, samples were left to stand for 5 minutes, after which saturated $\mathrm{NaCl}(3 \mathrm{~mL})$ was added to aid solvent separation. Samples were inverted manually before being centrifuged for 5 minutes at $3000 \mathrm{rpm}$ at room temperature. The hexane phase was recovered, passed through a $0.22 \mu \mathrm{m}$ nylon filter and collected in a $1 \mathrm{~mL}$ amber glass vial. Samples $(0.4 \mathrm{~mL})$ were spiked with a standard solution $(0.4 \mathrm{~mL})$ prior to $20 \mu \mathrm{L}$ being injected into the HPLC system.

\subsection{Sample preparation for $\beta$-carotene and total carotenoid analysis}


The samples were treated according to the methods described by HarvestPlus (Rodriguez-Amaya and Kimura, 2004). Each of the food samples was homogenized using a domestic blender (Multi-quick, Braun 3000) and 3 independent replicates between 0.5-2.5 g (wet weight) were collected. THF:methanol $(1: 1,50 \mathrm{~mL})$ was added to the sample, which was allowed to stand for 5 minutes before the mixture was homogenized using a polytron for 1 minute and, subsequently, filtered through a porosity 2-sintered glass funnel under vacuum and rinsed with THF:methanol until there was no colour left in the filtrate. PE (20 mL) was added to a $500 \mathrm{~mL}$ separating funnel, and the extracts poured into the separating funnel, followed by $50 \mathrm{~mL}$ of $10 \% \mathrm{NaCl}$ to aid separation. After washing thrice with $200 \mathrm{~mL}$ of deionised water, the upper PE phase, which contained the extract, was collected in a $100 \mathrm{~mL}$ flask. The PE phase was dewatered by the addition of anhydrous sodium sulphate, filtered into a $50 \mathrm{~mL}$ volumetric flask through glass wool, and made up to volume with PE. At this stage, spectrophotometer readings were analysed to determine total carotenoid content. Twenty millilitres of extract were collected in a glass vial and brought to dryness using nitrogen. $0.5 \mathrm{~mL}$ of THF:methanol (1:1) was added to reconstitute the sample and, finally, $5 \mu \mathrm{L}$ of reconstituted sample injected on to the HPLC.

\subsection{HPLC analysis}

An Agilent 1200 series normal phase high performance liquid chromatography (NP-HPLC) system was used, equipped with an isocratic pump, thermostated austosampler set to $6^{\circ} \mathrm{C}$ and a multiple wavelength detector. A Pinnacle II silica short narrow-bore column (50 mm x $2.1 \mathrm{~mm}$ I.D.), with a $3 \mu \mathrm{m}$ particle size from Restek (Bellefonte, USA), was used for analysis. Separation was performed at $30^{\circ} \mathrm{C}$ using an isocratic mixture of $0.5 \%$ ethyl acetate in hexane, delivered at a flow rate of $0.4 \mathrm{~mL} / \mathrm{min}$. Detection for $\alpha$ and $\gamma$-tocopherol was at $296 \mathrm{~nm}$ whereas detection of retinyl acetate and retinyl palmitate was at $326 \mathrm{~nm}$. The injection volume was $20 \mu \mathrm{L}$ and the total run time for each routine injection was 30 minutes. 
Retention times for retinyl palmitate, retinyl acetate, $\alpha$-tocopherol and $\gamma$-tocopherol were 1.1 minutes, 2.2 minutes, 3.5 minutes and 8.3 minutes, respectively (Fig. 1).

For the analysis of $\beta$-carotene, an Agilent 1200 series reverse phase high performance liquid chromatography (RP-HPLC) system was used equipped with a quaternary pump, thermostated autosampler and diode array detector. A YMC C30 column (250 mm x $4.6 \mathrm{~mm}) \mathrm{with}$ a $5 \mu \mathrm{m}$ particle size from YMC (Europe $\mathrm{GmbH}$ ) was used for the analysis. Separation was performed at $25^{\circ} \mathrm{C}$ using an isocratic mixture of $80: 20$ methanol:MTBE delivered at a flow rate of $1 \mathrm{~mL} / \mathrm{min}$. Detection of $\beta$-carotene was at $450 \mathrm{~nm}$. The injection volume was $5 \mu \mathrm{L}$ and total run time for each routine injection was 40 minutes. Retention time for $\beta$-Carotene was 30 minutes (Fig. 2).

\subsection{Spectrophotometer analysis}

A UV visible Cecil's Super Aquarius CE9200 9000 series spectrophotometer was used to measure absorbance at $450 \mathrm{~nm}$ in glass cuvettes for total carotenoid analysis.

\subsection{Limit of Detection (LOD), Limit of Quantification (LOQ) and Linearity}

Six standard solutions of retinyl acetate, retinyl palmitate $(0.2-5 \mu \mathrm{g} / \mathrm{mL}), \alpha$-tocopherol $(5-75 \mu \mathrm{g} / \mathrm{mL})$ and $\gamma$-tocopherol $(1-50 \mu \mathrm{g} / \mathrm{mL}) \mathrm{were}$ prepared at different concentrations by diluting the stock solutions using hexane. Linear calibration curves, at six different concentrations, were defined by best-fit line equations (Table 2). The limit of detection (LOD) and limit of quantification (LOQ) were determined using the signal- 
to-noise ratio (S/N) as shown in Table 2. Spiking of samples was used to verify the recovery of the vitamins tested (Trisconi, Campos-Gimenez,

\section{Jaudzems and Dowell, 2012).}

In the case of $\beta$-carotene, four standard solutions $(0.001-0.1 \mathrm{mg} / \mathrm{mL})$ were prepared at different concentrations following the dilution of the stock solutions using THF:methanol. A linear concentration curve was defined by the line of best-fit (Table 2). LOD and LOQ were calculated using LINEST function in Excel and shown in Table 2.

\subsection{Quality assurance}

The accuracy of the method was verified by analysing the certified reference material (ERM-BD600, IRRM). The expanded uncertainty for $\alpha$ tocopherol was greater than the absolute differences between the mean and measured value, and the certified value. The mean measured value was, therefore, not significantly different from the certified value; hereby demonstrating the validity of the method (Linsinger, 2005).

\subsection{Statistical methods}

The experimental results were subject to statistical analysis using Excel 2010 and SPSS package v.17.0. A two-sided unpaired T test at $p=0.05$ (with 95\% confidence interval) was used to examine mean differences between meat- and vegetable-based varieties. The data were further subjected to ANOVA at $p=0.05$ to examine differences between brands and replicate $(\mathrm{n}=3)$ measurements. Power analysis as function of effect size (0.05) on the sample size was determined using ${ }^{\circledR}$ Package 'PWR' Champely, S. (2015). 


\subsection{Results and Discussion}

The concentration of vitamin A from pre-formed sources, in the form of retinyl acetate and retinyl palmitate, provitamin A sources, in the form of $\beta$-carotene and total carotenoids, and vitamin E, in the form of $\alpha$-tocopherol and $\gamma$-tocopherol, from eight commercial 'ready-to-feed' infant foods are presented in Table 3.

There was no significant difference between the two varieties of meat- and vegetable-based infant food products at the 95\% significance level for $\alpha$-tocopherol $(p=0.460), \gamma$-tocopherol $(p=0.685)$, retinyl palmitate $(p=0.198)$, retinyl acetate $(p=0.688), \beta$-carotene $(p=0.552)$ and total carotenoids ( $p=0.942$ ). It was thought there might be differences between meat- and vegetable-based products, as pre-formed vitamin A is obtained mainly from animal sources and pro-vitamin A from plants, but this was not the case.

The results for vitamin A and E content in the selected infant food products were further subjected to both single factor with replication and two factor ANOVA without replication analysis. The calculated F value, after ANOVA between brands, showed a significant difference between brands for all forms of vitamin A and E. The calculated $p$-value (retinyl acetate $p=6.58 \mathrm{e}$-30, retinyl palmitate $p=1.5 \mathrm{e}-18$, $\beta$-carotene $p=1.93 \mathrm{e}$ 15 , total carotenoids $p=8.11 \mathrm{e}-17$, $\alpha$-tocopherol $p=2.15 \mathrm{e}-41, \gamma$-tocopherol $p=9.09 \mathrm{e}-13$ ) was significantly lower than the critical $p$-value at 0.05 . The calculated F value, for the ANOVA within groups (between the replicates), showed no significant difference (retinyl acetate $p=1.00$, retinyl palmitate $p=0.16, \beta$-carotene $p=0.68$, total carotenoids $p=1.00, \alpha$-tocopherol $p=0.086$, $\gamma$-tocopherol $p=0.99$ ), which indicates the consistency 
of measurements. Furthermore, the power analysis, as function of effect size (0.05), demonstrated a minimum sample size of eight had a power of $0.85\left({ }^{\circledR}\right.$ Package 'PWR'. Champely, S. 2015).

Dietary intake of vitamin A is a combination of both pre-formed and pro-vitamin A sources, but the bioavailability of different sources varies between different forms. Pre-formed vitamin A, such as retinyl palmitate, is absorbed rapidly, whereas pro-vitamin A carotenoids have poor absorption rates (Preedy, 2012). Traditionally, vitamin A activity has been described in RE, which takes into consideration the different bioavailabilities (WHO \& FAO, 1967). All forms of vitamin A tested in this study were converted to RE in order to calculate estimated total daily intakes. Table 4 shows the conversion factors used. It is important to be aware that RE are based on certain assumptions regarding absorption and, ultimately, the quantity that is converted to retinol. For example, studies have shown $\beta$-carotene absorption ranges between $3.6 \%$ and $28.1 \%$ from various food sources (Tang, 2010). The conversion factor used here was based on the conversion of $\beta$-carotene and carotenoids from a mixed diet.

The vitamin E potential of foods can be expressed as $\alpha$-tocopherol equivalents ( $\alpha$-TE) (Jiang, Christen, Shigenaga and Ames, 2001). In the UK, vitamin $\mathrm{E}$ is expressed as $\alpha$-TE on infant formula labelling and, therefore, $\alpha$-TE were used to represent vitamin $\mathrm{E}$ content in the diet for this study. Based on vitamin E potential, $1 \mathrm{mg}$ of $\alpha$-tocopherol is equal to $1 \mathrm{mg}$ of $\alpha$-TE, and $1 \mathrm{mg}$ of $\gamma$-tocopherol is equal to $0.1 \mathrm{mg}$ of $\alpha$-TE. The $\gamma$ tocopherol content of samples was, therefore, converted to $\alpha$-TE to represent the true value in calculation of the total daily intake, as shown in

Table 5. 
It is essential to examine the entire nutrient daily intake when assessing the nutrient quality of complementary foods. To estimate the total daily dietary intake of an infant, based on the consumption of commercial 'ready-to-feed' infant foods and infant formula, a standardised menu has been created, as suggested by Zand et al. (2012) based on manufacturers' feeding recommendations (Table 5). The volume of ingested meals is based on the gastric capacity of an infant (30 g/ kg body weight/ day) in accordance with the Committee of Medical Aspect of food and nutrition policy (COMA) Weaning and Weaning Diet report (1994). Furthermore, the estimated milk consumption used in the standard menu is $600 \mathrm{~mL}$, as advised by COMA for infants up to 12 months.

The RNI of vitamin A for infants is based on the amount present in breast milk from well-nourished, healthy mothers, and is set at $350 \mu \mathrm{g} /$ day for a 7-12 month old infant. The Department of Health (DOH) also recommends that regular daily intakes of vitamin A should not exceed 900 $\mu \mathrm{g} /$ day for infants.

From the standardised menu used in this study, the infant diet would exceed the recommended upper intake dose by $193 \%$ and the RNI by $497 \%$. This could cause numerous negative effects for the infant. The vitamin A contribution from infant formula (396 $\mu \mathrm{g}$ ) already exceeds the RNI by 13\%. Generally, the vitamin A in infant formula will be pre-formed vitamin A, retinol and retinyl esters (Koletzko, et al., 2005). Vitamin A toxicity is related to pre-formed vitamin A content and not pro-vitamin A sources. More research is needed to establish whether subclinical vitamin A toxicity is a concern in certain populations, including infants. However, the majority of the vitamin A in this study was provided by carotenoids ( $\beta$-carotene and total carotenoids), i.e. pro-vitamin A source, which are thought to have fewer negative effects. This might be because carotenoids are not stored in the liver like retinol, but are deposited throughout the body in fat cells, adrenal glands and other fatty tissues in 
addition to their absorption and conversion rates. However, when only pre-formed vitamin A was considered, food sources contribute 58.3\% of the RNI, which might lead to deficiency when milk intake is compromised or reduced after the first year of life. Furthermore, when the carotenoid content is removed from the standardised menu, the total daily intake was reduced to $600 \mu \mathrm{g}$ RE, which is below the UL but still higher than the RNI. NDNS data indicate that intakes are above the RNI (Public Health England, 2014). However, due to the lack of knowledge concerning toxicity and bioavailability of the different vitamin A forms in infants, further investigations are required.

Breast milk concentrations of vitamin A vary widely; $150 \mu \mathrm{g} / \mathrm{L}-1100 \mu \mathrm{g} / \mathrm{L}$ of preformed vitamin A, depending on maternal diet and vitamin A status (Thompkinson \& Kharb, 2007). Therefore, if an infant is being breastfed, the mother's diet is also an essential factor for the infant's nutritional status. If an infant receives human milk with a high vitamin A concentration then vitamin A intakes from pre-formed sources will be higher than those calculated in this study $(1100 \mu \mathrm{g} / \mathrm{L}=660 \mu \mathrm{g} / 600 \mathrm{~mL})$. At the other end of the spectrum, if an infant is consuming human milk low in vitamin A then deficiency issues might arise $(150 \mu \mathrm{g} / \mathrm{L}=90 \mu \mathrm{g} / 600 \mathrm{~mL})$.

It is important to mention that, in 2001, the US Food and Nutrition Board introduced a new conversion factor, retinol activity equivalents (RAE), due to changes in knowledge about carotenoid bioconversion. The RAE of $\beta$-carotene was defined as $12 \mu \mathrm{g}$ instead of $6 \mu \mathrm{g}$ (Food and Nutrition Board, Institute of Medicine, 2001). Vitamin A in infant formula in the UK is expressed in RE and, therefore, RE was used in this study to express vitamin A content. There is a large debate over the bioavailability of carotenoids, as their bioavailability is dependent on numerous factors including food matrix, amounts of fat ingested, and food processing methods. Although carotenoids with pro-vitamin A activity are precursors of vitamin A excess intake has not been associated with vitamin A toxicity in humans because carotene conversion is regulated by vitamin A 
status. However, high intakes should still be approached with caution due to human studies conducted in the 1990s among smokers who had been previously exposed to asbestos where high doses of $\beta$-carotene were associated with increased risk of lung cancer (Tanvetyanon \& Bepler, 2008). To date, there is insufficient scientific evidence to set a UL for $\beta$-carotene and further research is required. Furthermore, as the equivalence factors for both retinol and carotenoids are unknown in infants they may not be adequate (Koletzko, et al., 2005).

As vitamin E requirements are based on PUFA intakes, it is difficult to set up dietary reference values since the range of PUFA intakes in the UK varies widely and, therefore, acceptable ranges of intake are more appropriate than a fixed level. In addition, the relationship between PUFA intake and vitamin E requirements is not linear. Some committees, however, in other countries, such as the US, have calculated vitamin E requirements as $0.4 \mathrm{mg} \alpha$-TE/ g of dietary PUFA, based on the PUFA content of the diet, which is also used in the UK for fortification of infant formulas (Department of Health, 1991).

Based on UK guidelines for fat intake, and vitamin E requirements as $0.4 \mathrm{mg} \alpha$-TE/g dietary PUFA, for a 7-12 month infant, the recommended daily intake is $5.625 \mathrm{~g}$ /day. Based on this assumption, infants aged 7-12 months require $2.25 \mathrm{mg} /$ day of $\alpha$-TE. The US Institute of Medicine recommended an actual intake for infants aged 7-12 months of $5 \mathrm{mg}$ /day of $\alpha$-tocopherol rather than $\alpha$-TE (Food and Nutrition Board, Institute of Medicine, 2000). Taking into consideration that the major contributor of vitamin $\mathrm{E}$ in the US diet is $\gamma$-tocopherol this recommendation does not take into account other forms of vitamin E that may potentially be important for human health. It is also higher than the UK recommendation even for adults (3-4 mg/day). 
It is also apparent from national feeding studies in the US that, after one year, vitamin E intake is inadequate, which might be explained by the reduction in infant formula (Butte, et al., 2010). From the finding of this study, however, it appears that the majority of vitamin E provided by the infant formula is in the form of $\alpha$-tocopheryl acetate, with only a small amount (18.9\%) coming from commercial 'ready-to-feed' infant foods.

It is important to highlight that breast milk contains less vitamin E than infant formula, $0.66 \mathrm{mg} / 100 \mathrm{~mL}$ compared with $1.4 \mathrm{mg} / 100 \mathrm{ml}$

(Thompkinson \& Kharb, 2007). Therefore, breastfed infants will be closer to recommended intakes for infants of 7 to 12 months of age. However, breast milk concentrations will vary due to the maternal diet and the vitamin E status of the mother. Hence, if milk intake is compromised, reduced or breast milk concentrations are low, there may be a cause for concern over adequacy of the infant's diet in terms of vitamin E requirements.

Moreover, the bioavailability of vitamin E is largely unclear with studies ranging from $10-79 \%$. This highlights the importance of undertaking further research to understand the absorption and metabolism efficacy of the different forms of vitamin E as well as antioxidant and nonantioxidant properties (Borel, et al., 2013).

The main limitations in calculating the vitamin intake, as described, are assumptions about consumption and retention by the infant, and maternal breast milk composition. Also, it does not take into consideration wastage and ignores any contribution from snacks or homemade foods.

\section{Conclusions}


The concentrations of vitamin A (retinyl acetate, retinyl palmitate and $\beta$-carotene) and $\mathrm{E}$ ( $\alpha$ and $\gamma$-tocopherol) were determined quantitatively by HPLC. The estimated total daily intake of vitamin A, converted to RE, from a combination of commercial complementary infant foods and infant formula, based on the standardised menu, was found to exceed upper intake levels for infants (900 $\mu \mathrm{g}$ RE/ day). It is worth mentioning that the contribution of vitamin A from infant formula alone was found to be $396 \mu \mathrm{g}$ RE, which exceeds the RNI of $350 \mu \mathrm{g}$ RE for infants from seven to twelve months of age by $13 \%$. The remaining vitamin A content was from carotenoids ( $\beta$-carotene and total carotenoids), which are considered potentially less harmful. However, further studies into the bioavailability of different forms of vitamin A in infants, and the effect of excess intake are necessary. Pre-formed vitamin A food sources contributed 58.3\% of the RNI and, therefore, if the contribution from (breast or formula) milk is reduced, deficiency might become an issue. Parents should be made aware of the impact that a reduction in fortified infant formula use or breast milk might have on the nutritional composition of an infant's diet.

The total daily intake of vitamin E, based on a diet consisting of complementary ready-to-feed infant foods and infant formula, was 10.4 mg/ day of $\alpha$-TE, which is greater than the recommended adequate intake ( $5 \mathrm{mg} / \mathrm{day} \alpha$-tocopherol) set by the US. However, $81 \%$ of the vitamin $\mathrm{E}$ was provided from infant formula with only a small contribution from infant food products, which may become a concern when milk intake is compromised or reduced as it is after the first year of life.

\section{Acknowledgements}


The authors would like to thank Mrs Devyani Amin and Mrs Atiya Raza for their support and assistance in this work. In addition the authors would like to thank Dr Aurélie Bechoff and Dudley Farman from the Natural Resources Institute at the University of Greenwich for their support and use of facilities.

\section{References}

Baydas, G., Karatas, F., Gursu, M. F., Bozkurt, H. A., Ilhan, N., Yasar, A., \& Canatan, H. (2002). Antioxidant vitamin levels in term and preterm infants and their relation to maternal vitamin status. Archives of medical research, 33(3), 276-80.

Borel, P., Preveraud, D., \& Desmarchelier, C. (2013). Bioavailability of vitamin E in humans: an update. Nutrition reviews, 71(6), 319-31.

Butte, N. F., Fox, M. K., Briefel, R. R., Siega-Riz, A. M., Dwyer, J. T., Deming, D. M., \& Reidy, K. C. (2010). Nutrient intakes of US infants, toddlers, and pre-schoolers meet or exceed dietary reference intakes. Journal of American Dietetic Association, 110 (12 Supplement), S27-37.

Chávez-Servín, J. L., Castellote, A. I., \& Lopez-Sabater, M. C. (2006). Simultaneous analysis of Vitamins A and E in infant milk-based formulae by normal-phase high-performance liquid chromatography-diode array detection using a short narrow-bore column. Journal of Chromatography A, 1122(1-2), 138-43.

Committee on Toxicity (2012). Second draft statement on the potential risks from high levels of vitamin A in the infant diet. COT of chemicals in food, consumer products and the environment. TOX/2012/41. Available at: http://cot.food.gov.uk. 
Committee on Toxicity (2014). Statement on the potential risks from high levels of vitamin A in the infant diet. COT of chemicals in food, consumer products and the environment. COT statement 2013/03. Available at: http://cot.food.gov.uk.

Department of Health (1991). Dietary Reference Values for Food Energy and Nutrients for the United Kingdom: Report of the Panel on Dietary Reference Values of the Committee on Medical Aspects of Food Policy, Stationery Office.

Devereux, G., Turner, S. W., Craig, L. C., McNeill, G., Martindale, S., Harbour, P. J., Helms, P. J., \& Seaton, A. (2006). Low maternal vitamin E intake during pregnancy is associated with asthma in 5-year-old children. American Journal of Respiratory and Critical Care Medicine, 174(5), 499-507.

Diplock, A. T., Charleux, J. L., Crozier-Willi, G., Kok, F. J., Rice-Evans, C., Roberfroid, M., Stahl, W., \& Vina-Ribes, J. (1998). Functional food science and defence against reactive oxidative species. British Journal of Nutrition, 80 Supplement 1, S77-112.

Eitenmiller, R., \& Lee, J. (2004). Vitamin E Food Chemistry, Composition, and Analysis, NY, USA: Marcel Dekker Ink.

Food and Nutrition Board, Institute of Medicine (2000). Dietary Reference Intakes for Vitamin C, Vitamin E, Selenium, and Carotenoids. Washington, D.C.: National Academy Press.

Food and Nutrition Board, Institute of Medicine (2001). Dietary Reference Intakes for Vitamin A, Vitamin K, Arsenic, Boron, Chromium, Copper, Iodine, Iron, Manganese, Molybdenum, Nickel, Silicon, Vanadium, and Zinc. Washington, D.C.: National Academy Press. 
Food Standard Agency (2014). McCance and Widdowson's the composition of foods. Royal Society of Chemistry.

Greene, H. L., Hambidge, K. M., Schanler, R., \& Tsang, R. C. (1988). Guidelines for the use of vitamins, trace elements, calcium, magnesium, and phosphorus in infants and children receiving total parenteral nutrition: report of the Subcommittee on Pediatric Parenteral Nutrient Requirements from the Committee on Clinical Practice Issues of the American Society for Clinical Nutrition. American Journal of Clinical Nutrition, 48(5), 1324-42.

Jiang, Q., Christen, S., Shigenaga, M. K., \& Ames, B. N. (2001). Gamma-tocopherol, the major form of vitamin E in the US diet, deserves more attention. American Journal of Clinical Nutrition, 74(6), 714-22.

Klein, B. P., \& Kurilich, A. C. (2000). Processing Effects on Dietary Antioxidants from Plant Foods. HortScience, 35(4), 580-584.

Koletzko, B., Baker, S., Cleghorn, G., Neto, U. F., Gopalan, S., Hernell, O., Hock, Q. S., Jirapinyo, P., Lonnerdal, B., Pencharz, P., Pzyrembel, H., Ramirez-Mayans, J., Shamir, R., Turck, D., Yamashiro, Y., \& Zong-Yi, D. (2005). Global standard for the composition of infant formula: recommendations of an ESPGHAN coordinated international expert group. Journal of Paediatric Gastroenterology and Nutrition, 41(5), 58499.

Lennox, A., J, Sommerville., Ong, K., Henderson, H. \& Allen, R. (2013). Diet and nutrition survey of infants and young children, 2011. Public Health England, 1-107. 
Lee, I. M., Cook, N. R., Gaziano, J. M., Gordon, D., Ridker, P. M., Manson, J. E., Hennekens, C. H., \& Buring, J. E. (2005). Vitamin E in the primary prevention of cardiovascular disease and cancer: the Women's Health Study: a randomized controlled trial. Journal of the American Medical Association, 294(1), 56-65.

Linsinger, T. (2005). Comparison of a measurement result with the certified value. ERM European Commission. Geel, Belgium.

Preedy, V. R. (2012). Vitamin A and Carotenoids: Chemistry, Analysis, Function and Effects, Cambridge, UK: The Royal Society of Chemistry.

Public Health England (2014). National Diet and Nutrition Survey. Results from Years 1, 2, 3 and 4 (combined) of the Rolling Programme (2008/2009 - 2011/2012). Food Standards Agency. Available at: https://www.gov.uk.

Rietjens, I. M., Boersma, M. G., Haan, L., Spenkelink, B., Awad, H. M., Cnubben, N. H., van Zanden, J. J., Woude, H., Alink, G. M., \& Koeman, J. H. (2002). The pro-oxidant chemistry of the natural antioxidants vitamin C, vitamin E, carotenoids and flavonoids. Environmental Toxicology and Pharmacology, 11(3-4), 321-33.

Rodriguez-Amaya, D. B., Kimura, M., International Food Policy Institute \& Centro Internacional de Agricultua Tropical (2004). HarvestPlus Handbook for Carotenoid Analysis, International Food Policy Research Institute.

Suskind, R. M., \& Tontisirin, K. (2001). Nutrition, Immunity, and infection in Infants and Children, USA: Lippincott Williams \& Wilkins. 
Statista (2008). Brands of baby and junior foods ranked by number of users in the United Kingdom (UK) in 2014 (in 1,000 people).URL http://www.statista.com/statistics/303901/leading-baby-and-junior-food-brands-in-the-uk/. Accessed 01.09.2015.

Tang, G. (2010). Bioconversion of dietary provitamin A carotenoids to vitamin A in humans. American Journal of Clinical Nutrition, 91(5), 1468s-1473s.

Tanvetyanon, T., \& Bepler, G. (2008). Beta-carotene in multivitamins and the possible risk of lung cancer among smokers versus former smokers: a meta-analysis and evaluation of national brands. Cancer, 113(1), 150-7.

Thompkinson, D. K., \& Kharb, S. (2007). Aspects of Infant Food Formulation. Comprehensive Reviews in Food Science and Food Safety, 6(4), 79-102.

Trisconi, M. J., Campos-Gimenez, E., Jaudzems, G., \& Dowell, D. (2012). Determination of vitamin A in infant formula and adult nutritionals by UPLC-UV: First Action 2011.07. Journal of AOAC International, 95(2), 301-6.

Wagner, K. H., Kamal-Eldin, A., \& Elmadfa, I. (2004). Gamma-tocopherol-an underestimated vitamin? Annals of Nutrition and Metabolism, 48(3), 169-88.

WHO and FAO (1967). Requirements of vitamin A, thiamine, riboflavine and niacin: report of a joint FAO/WHO expert group, Rome, Italy, 617 September 1965. 
Zand, N., Chowdhry, B. Z., Pullen, F. S., Snowden, M. J., \& Tetteh, J. (2012). Simultaneous determination of riboflavin and pyridoxine by UHPLC/LC-MS in UK commercial infant meal food products. Food Chemistry, 135(4), 2743-9.

\section{Figure Caption}

Figure 1. HPLC chromatogram of: A. standard mixture and B. sample (1. retinyl palmitate -1.1 minutes, 2 . retinyl acetate -2.2 minutes, 3 . $\alpha$ tocopherol -3.5 minutes and 4. $\gamma$-tocopherol -8.3 minutes).

Figure 2. HPLC chromatogram of: A. standard mixture and B. sample (1. $\beta$-carotene - 30 minutes) 